\title{
Association between Sleep Duration and Obesity in Young Korean Adults
}

\author{
Shin Yi Jang ${ }^{1}$, Eun Young Ju², Kyung Min Park ${ }^{3}$, Sura Seo ${ }^{4}$, Su Jung Choi ${ }^{5}$, Chang Kwan Lee ${ }^{6}$, Heeran Chun ${ }^{7}$, Seung Woo Park \\ ${ }^{1}$ Division of Cardiology, Department of Medicine, Heart Vascular Stroke Institute, Samsung Medical Center, Sungkyunkwan University School of Medicine, Seoul; \\ ${ }^{2}$ Graduate School of Public Health, Seoul National University, Seoul; ${ }^{3}$ College of Liberal Studies, Seoul National University, Seoul; ${ }^{4}$ The National Health Insurance \\ Service, Seoul; ; Department of Nursing, Samsung Medical Center, Seoul; ${ }^{6}$ Department of Nursing, Korean Christian University, Seoul; ${ }^{7}$ Department of Health \\ Administration, Jungwon University, Goesan, Korea
}

Background: The purpose of this study was to investigate the association between number of sleep hours and obesity based on body mass index (BMI) after adjusting for socioeconomic position, health behaviors, and clinical factors.

Methods: Data from subjects aged 20-64 years $(\mathrm{n}=12,688)$ in the Korea National Health and Nutrition Examination Survey in 2007-2009 was analyzed. Subjects were divided into two groups according to age: 20-44 (young adults) and 45-64 years (middle-aged adults). With respect to sleep time, subjects were classified as short sleepers ( $<6 \mathrm{hr} /$ day), long sleepers ( $\geq 9 \mathrm{hr} /$ day), and normal sleepers (6-8.9 hr/day). Obesity was defined as a $B M I \geq 25$.

Results: The proportion of patients who were obese was $27.8 \%$. The distribution of short sleepers, long sleepers, and normal sleepers was $6.4 \%$, $13.7 \%$, and $79.9 \%$, respectively. The adjusted short sleeper and long sleeper odds ratios (OR) for obesity in young adults were significantly different from that in middle-aged adults after adjustment for confounding factors. In women, the adjusted short sleeper OR for obesity was 1.56 (95\% CI, 1.02-2.37).

Conclusion: This community-based random sample of Korean adults showed that women with short sleep duration may be at significant risk of obesity.

Key words: Short sleepers, Obesity, Body mass index, Young adult, Sex

\section{Introduction}

Obesity is a major public health burden in developed countries ${ }^{1-3}$ and is also a well-known risk factor of cardiovascular disease (CVD). Short sleep duration is associated not only with obesity ${ }^{4}$, but also with diabetes mellitus ${ }^{5}$, heart disease $e^{6-8}$, and death. ${ }^{9}$ An inverse relationship between inadequate sleep duration and obesity has been shown in young adults ${ }^{10}$, specifically in young women. ${ }^{11}$ Associations between sleep duration and health indicators differ according to factors such as race, culture, and sex. ${ }^{12}$ Koreans, in particular, are known to have relatively few sleep hours compared with those in other Organization for Economic Cooperation and Development (OECD) countries. ${ }^{13}$ However, few studies have focused on the association between sleep duration and obesity in the Korean population. Therefore, we investigated the association between sleep duration and obesity after adjusting for socioeconomic position, health behaviors, and other clinical factors.

\section{Methods}

\section{Study population}

Data were collected from the 2007-2009 Korea National Health and Nutrition Examination Survey (KNHANES) conducted by the Ministry of Health and Welfare of Korea. ${ }^{14}$ The survey applied a stratified, multistage probability sampling design to the South Korean population using a three-stage, stratified, systematic sampling method. The KNHANES included three questionnaires: a health interview survey, a health behavior survey, and a health examination. The health interview survey sample included 13,800 households and 31,705 household members from 600 districts. One of every three
*Corresponding author Seung Woo Park (iD http://orcid.org/0000-0002-2941-515X Division of Cardiology, Department of Medicine, Heart Vascular Stroke Institute, Samsung Medical Center, Sungkyunkwan University School of Medicine, 81 Irwon-ro, Gangnam-gu, Seoul 06351, Korea

Tel +82-2-3410-3419 Fax+82-2-2148-7973 E-mail parksmc@gmail.com

Received Oct. 12, 2015 Reviewed Nov. 24, 2015 Accepted Dec. 28, 2015
Copyright (C) 2016 Korean Society for the Study of Obesity

(a) This is an Open Access article distributed under the terms of the Creative Commons Attribution Non-Commercial License (http://creativecommons.org/licenses/by-nc/4.0/) which permits unrestricted non-commercial use, distribution, and reproduction in any medium, provided the original work is properly cited. 
health interview survey participants was selected for further participation in the health behavior survey and health examination. From the 2007-2009 KNHANES, 24,871 people aged one year and older were interviewed of the 31,705-person sample (response rate: 78.4\%). We analyzed data from subjects aged 20-64 years with weighted variables ( $\mathrm{n}=12,688 ; 6,495$ men and 6,193 women). The sample included 7,775 people aged 20-44 years (young adults; male 4,030 and female 3,745) and 4,913 people aged 45-64 years (middle-aged adults; male 2,465 and female 2,448).

The health interview questionnaire and health examination included several variables. Patients were divided in two groups according to age: 20-44 years and 45-64 years. Systolic blood pressure (SBP) and diastolic blood pressure (DBP) were measured after the subject had rested for five minutes in a sitting position. An average of three blood pressure measurements was used for data analysis. Blood samples were collected from the antecubital vein after overnight nil per os (NPO). Fasting plasma glucose, total cholesterol (TC), triglyceride (TG), and high density lipoprotein (HDL) levels were measured using enzymatic or colorimetric methods. Self-reported information on stress/depression status was obtained from the interviews, including usual stress perception and persistent depression for at least two weeks. Information on education level, monthly household income, family size, dietary consumption, regular physical activity, smoking status, alcohol consumption, employment status, hours worked per week, and sleep time in hours was also collected. A food frequency questionnaire (FFQ) consisting of 63 food items and the 24-hour recall method were used to document dietary consumption. Nutrient intake was calculated as a percentage of total daily energy consumption and the energy obtained from protein, fat, and carbohydrates. The study received ethical approval from the Institutional Review Board of Korea Centers for Disease Control and Prevention in Osong, Korea. Written informed consent was obtained from all participants in the study.

\section{Sleep duration}

Self-reported sleep duration was grouped according to number of sleep hours. Patients were classified into three categories: short sleepers ( $<6$ hours (h)/day), long sleepers ( $\geq 9 \mathrm{~h} /$ day), and normal sleepers $\left(6-8.9 \mathrm{~h} /\right.$ day). ${ }^{15-18}$ The sleep duration question was phrased as "How many hours do you usually sleep per day?"

\section{Obesity}

Body mass index (BMI) was calculated as weight in kilograms divided by the square of height in meters. Obesity was defined as a BMI $\geq 25 .{ }^{19,20}$

\section{Standing height measurement}

We measured subjects' standing height using anthropometry (SECA225, Germany SECA). First, they stood with heels together and toes apart. The subjects were checked to confirm that the back of the head, buttocks, and heels made contact with the backboard. Second, the head was aligned in the Frankfort horizontal plane. We used an anthropometric bar on the subjects' heads and measured the result to the nearest centimeter.

\section{Weight measurement}

Subjects were weighed in kilograms using a scale (GL-6000-20, CAS Korea), and the results was determined when gradation was stabilized after a set zero on the scale with no load.

\section{Socioeconomic factors}

The socioeconomic factors used in this study were education level and equivalent household monthly income. Education level was classified into three categories: 1) elementary school; six years or less of schooling, 2) middle/high school; 7-12 years of schooling, and 3) college, university; >12 years of schooling. Equivalent household monthly income (equivalent income) was calculated using the following formula created by the OECD ${ }^{21}: W_{i j}=Y_{i} / S_{i}{ }^{\varepsilon}$, where $Y_{i}$ is the $i^{\text {th }}$ household income, $S_{i}$ is the $\mathrm{i}^{\text {th }}$ household family size, and $W_{i j}$ is the equivalent income of the $j^{\text {th }}$ member in the $i^{\text {th }}$ household. Equivalent elasticity, $\varepsilon$, which is an equivalency of household size, was set to 0.5 . Equivalent income was then calculated by dividing the obtained monthly household income by the square root of family size. Equivalent income was categorized into three levels: low $(<130)$, middle (130-849), and high ( $\geq 849$ ). Employment status consisted of currently working or not working and included full-time and parttime positions. Finally, the number of hours worked per week included full- and part-time work.

\section{Health behavior factors}

A subject was identified as a current smoker if he or she had smoked within one year of the survey date. A subject was defined as 
a current drinker if he or she had consumed an alcoholic beverage within one year of the survey date. Regular physical activity was defined as having walked 30 minutes at a time, more than five days a week.

\section{Statistical analyses}

Differences in general characteristics, socioeconomic factors, health behaviors, and clinical data between non-obese and obese groups were analyzed using Student's $t$-tests for continuous variables and $\chi^{2}$-tests for categorical variables. The mean ( \pm standard error) of BMI by sleep duration (from less 5 to over 10) was determined for all groups, including by sex, and the 20-44 years and $45-64$ years groups were analyzed using one-way analysis of variance. Multiple logistic regression analysis was used to determine the association between sleep duration ( $<6$ hours vs $\geq 9$ hours vs $6-8.9$ hours) as the independent variable and obesity as the dependent variable after adjusting for age, sex, socioeconomic position, health behaviors, and other clinical factors. The sample weights proposed by the Korea Institute of Health and Social Affairs to estimate nationwide prevalence were applied for all analyses. ${ }^{22} P$ values less than 0.05 were reported as statistically significant. Data were analyzed with Statistical Analysis System (SAS) software, version 9.3 (SAS Inc., Cary, NC, USA).

\section{Results}

Of our total sample, $31.6 \%$ were obese. A significantly higher proportion of obese people had short sleep hours compared with normal sleep hours in the young adult group $(P<0.001)$. Generally, obese people were more likely to be male, under stress, less educated, and currently employed compared to non-obese people $(P<0.05)$. In contrast, the proportion of people who regularly engaged in regular physical activity was higher among non-obese people than obese people $(P<0.001)$. TG levels in the obese group were higher than those of the non-obese group $(P<0.01)$ (Table 1$)$.

The adjusted odds ratios (OR) of short sleep hours [1.56 (95\% Confidence Interval (CI), 1.02-2.37)] and long sleep hours [2.41 (95\% CI, 1.28-4.54)] were statistically significant in young women after adjusting for potential confounders (Table 2). Furthermore, in young women, shorter the sleep duration was associated with higher BMI (Fig. 1).

\section{Discussion}

Although long sleep duration was found to be associated with obesity in both sexes in the young age group in this study, obesity was associated with short sleep duration in the 20-44 years group in women. The results of this present study are similar to those of an earlier study. The United States (US) civilian noninstitutionalized population study that used the National Health and Nutrition Examination Survey I showed an association between short sleep duration and obesity in women. ${ }^{23}$ Additionally, an internal medicine clinic patient study showed that short sleep time predicted obesity in women aged 18 to 49 years in the US. ${ }^{24}$

Multiple studies have been conducted in various countries and have indicated that there is an association between obesity and sleep duration. For example, adults in Australia ${ }^{17}$ and the US ${ }^{25}$ showed an association between obesity and short/long sleep duration. Additionally, studies of young Swedish women ${ }^{11}$, a community prospective cohort study in Zurich ${ }^{26}$, Brazilian adults ${ }^{27}$, and a populationbased study in the US ${ }^{28}$ showed that obesity was associated with short sleep duration. The Insulin Resistance Atherosclerosis Study Family Study, which measured abdominal fat using computed tomography ${ }^{29}$, showed an association between short sleep duration and obesity in adults younger than 40 years. Short sleep duration has been shown to be associated with reduced leptin, elevated ghrelin, and increased BMI. ${ }^{30,31}$ Furthermore, sex hormones and reproductive events may explain the differences between men and women. ${ }^{32}$ Decreases in sleep duration and quality of sleep were observed in postpartum women. In a Korean study, Park et al. ${ }^{33}$ determined that short and long sleep durations were associated with psychiatric disorders and obesity. Unfortunately, they did not analyze their data according to age or sex. However, the Penn State Cohort ${ }^{34}$ and the White Hall II Study ${ }^{12}$ did not show a significant association between short sleep duration and obesity. Although a causal effect between long sleep hours and obesity has not be established, a previous study showed that long sleepers were more likely to experience obesity, depression, lower SEP, and social isolation. ${ }^{35}$

In the present study, obesity was associated with short sleep duration only in women, although longer sleep duration was associated with obesity in both sexes in the young age group. The association between sleep duration and BMI in women is not in accordance with the large epidemiologic study by Kripke et al. ${ }^{9}$, which reported a U- 
Table 1. Distribution of general characteristics, sleep hours, mental stress, socioeconomic position, health behaviors, and clinical factors by age group and body mass index

\begin{tabular}{|c|c|c|c|c|c|c|c|c|c|}
\hline \multirow[b]{2}{*}{ Variables } & \multicolumn{3}{|c|}{$20-64$ years $(n=12,688)$} & \multicolumn{3}{|c|}{$20-44$ years $(n=7,775)$} & \multicolumn{3}{|c|}{$45-64$ years $(n=4,913)$} \\
\hline & $\begin{array}{l}\text { Non-obese } \\
(\mathrm{n}=8,679)\end{array}$ & $\begin{array}{c}\text { Obese } \\
(n=4,009)\end{array}$ & $P$ value $^{*}$ & $\begin{array}{l}\text { Non-obese } \\
(n=5,648)\end{array}$ & $\begin{array}{c}\text { Obese } \\
(n=2,127)\end{array}$ & $P$ value $^{*}$ & $\begin{array}{l}\text { Non-obese } \\
(n=3,031)\end{array}$ & $\begin{array}{c}\text { Obese } \\
(\mathrm{n}=1,882)\end{array}$ & $P$ value $^{*}$ \\
\hline & \multicolumn{9}{|c|}{ Percentages } \\
\hline Age, years, mean (SD) & $39.3(16.7)$ & $42.9(14.5)$ & 0.334 & $32.1(10.5)$ & $33.8(8.76)$ & 0.077 & $52.7(6.06)$ & $53.2(6.07)$ & 0.889 \\
\hline Sex, female & 53.4 & 38.5 & $<0.001$ & 54.1 & 32.3 & $<0.001$ & 52.1 & 46.0 & $<0.001$ \\
\hline Sleep hours, mean (SD) & $6.95(1.49)$ & $6.77(1.46)$ & 0.925 & $7.07(1.50)$ & $6.84(1.38)$ & 0.699 & $6.74(1.10)$ & $6.70(1.30)$ & 0.846 \\
\hline Sleep hours & & & $<0.001$ & & & $<0.001$ & & & 0.132 \\
\hline$\geq 9$ & 8.2 & 6.4 & & 9.1 & 6.7 & & 6.5 & 6.1 & \\
\hline $6-9$ & 82.2 & 79.9 & & 83.0 & 82.1 & & 79.2 & 77.3 & \\
\hline$<6$ & 9.6 & 13.7 & & 7.9 & 11.2 & & 14.3 & 16.6 & \\
\hline Perceived stress & 29.2 & 31.6 & 0.025 & 31.6 & 35.7 & 0.004 & 24.5 & 27.0 & 0.080 \\
\hline Perceived depression & 13.1 & 13.2 & 0.937 & 11.7 & 11.2 & 0.594 & 15.7 & 15.3 & 0.721 \\
\hline Education level & & & $<0.001$ & & & 0.003 & & & 0.001 \\
\hline College, University & 46.8 & 39.4 & & 61.4 & 57.3 & & 24.4 & 29.4 & \\
\hline Middle/High school & 44.2 & 46.1 & & 37.8 & 41.5 & & 56.0 & 51.2 & \\
\hline Elementary school & 9.0 & 14.5 & & 0.8 & 1.2 & & 19.6 & 19.4 & \\
\hline Income level $^{\dagger}$ & & & 0.053 & & & 0.151 & & & 0.522 \\
\hline High & 29.7 & 25.0 & & 32.2 & 31.3 & & 25.0 & 25.2 & \\
\hline Middle & 33.3 & 31.7 & & 32.6 & 30.6 & & 34.0 & 32.4 & \\
\hline Lower & 40.5 & 43.3 & & 35.2 & 38.1 & & 41.0 & 42.4 & \\
\hline Walking practice, Yes & 82.3 & 79.1 & $<0.001$ & 83.0 & 77.8 & $<0.001$ & 81.0 & 80.7 & 0.766 \\
\hline Current smoker, Yes & 4.7 & 3.9 & 0.212 & 5.6 & 3.0 & 0.494 & 3.1 & 2.7 & 0.806 \\
\hline Current drinker, Yes & 91.5 & 91.2 & 0.579 & 94.6 & 95.2 & 0.396 & 85.8 & 86.8 & 0.339 \\
\hline Employment status, Yes & 64.7 & 71.0 & $<0.001$ & 63.7 & 71.6 & $<0.001$ & 66.4 & 70.6 & 0.004 \\
\hline \multirow[t]{2}{*}{ Hours worked per week, mean (SD) } & $45.9(22.5)$ & $48.8(21.2)$ & 0.081 & $45.1(21.6)$ & $48.9(20.6)$ & 0.088 & $47.5(22.7)$ & $48.7(23.7)$ & 0.288 \\
\hline & \multicolumn{9}{|c|}{ Mean (SD) } \\
\hline Systolic blood pressure (mmHg) & $112.2(24.2)$ & $120.8(21.1)$ & 0.442 & $108.4(19.5)$ & $117.2(17.5)$ & 0.639 & $119.1(20.9)$ & $124.9(19.9)$ & 0.445 \\
\hline Diastolic blood pressure (mmHg) & $74.7(18.6)$ & $81.0(15.2)$ & 0.101 & $72.8(16.5)$ & $79.6(13.8)$ & 0.083 & $78.3(14.3)$ & $82.5(13.4)$ & 0.564 \\
\hline Fasting plasma glucose (mg/dL) & $93.0(23.2)$ & $100.9(29.1)$ & 0.068 & $90.2(20.2)$ & 95. (22.6) & 0.325 & $98.2(23.6)$ & $106.7(32.9)$ & 0.059 \\
\hline Total cholesterol (mg/dL) & $180.5(42.8)$ & $195.2(44.3)$ & 0.446 & $174.2(40.5)$ & $192.6(44.2)$ & 0.249 & $192.2(36.8)$ & $198.1(42.9)$ & 0.346 \\
\hline Triglyceride (mg/dL) & $115.5(114.5)$ & $173.5(165.8)$ & 0.003 & $104.2(103.7)$ & $171.7(163.7)$ & 0.030 & $136.5(118.3)$ & $175.5(166.1)$ & 0.028 \\
\hline High density lipoprotein (mg/dL) & $49.2(17.7)$ & $43.5(12.6)$ & 0.509 & $49.9(17.2)$ & $43.3(11.9)$ & 0.805 & $48.0(12.6)$ & $43.8(12.1)$ & 0.918 \\
\hline Body mass index & $21.8(1.86)$ & $27.4(2.53)$ & $<0.001$ & $21.5(2.25)$ & $27.6(2.77)$ & $<0.001$ & $22.3(1.65)$ & $27.1(2.17)$ & $<0.001$ \\
\hline Waist circumference $(\mathrm{cm})$ & $76.2(11.1)$ & $90.6(9.50)$ & 0.052 & $74.8(10.5)$ & $90.4(9.69)$ & 0.295 & $78.8(8.26)$ & $90.7(7.81)$ & 0.058 \\
\hline Energy (kcal/day) & $1,930.7(1,101.7)$ & $2,036.7(1,149.0)$ & 0.634 & $1,966.8(1,062.7)$ & $2,113.5(1,150.6)$ & 0.197 & 1,865.4 (959.8) & $1,954.7(1,069.7)$ & 0.518 \\
\hline Protein (g/day) & $70.0(49.5)$ & $73.6(50.1)$ & 0.806 & $72.0(50.4)$ & $77.6(50.5)$ & 0.818 & $66.4(38.5)$ & $69.2(44.3)$ & 0.877 \\
\hline Fat (g/day) & $40.3(40.7)$ & $40.8(40.8)$ & 0.585 & $44.8(39.8)$ & $47.4(38.8)$ & 0.299 & $32.1(33.4)$ & $33.6(37.4)$ & 0.776 \\
\hline Carbohydrates (g/day) & $308.0(169.1)$ & $318.4(163.3)$ & 0.191 & $304.7(159.4)$ & $313.0(160.9)$ & 0.029 & $314.0(157.9)$ & $324.0(153.9)$ & 0.709 \\
\hline
\end{tabular}

Regular physical activity: if subject had walked 30 minutes at a time, more than five days a week; Current smoker: if subject had smoked within one year of the survey date; Current drinker: if subject had consumed an alcoholic beverage within one year of the survey date; Employment status: if subject is currently working.

${ }^{*}$ Student's $t$-test or $\chi^{2}$-test; ${ }^{\dagger}$ Equivalent household monthly income.

shaped relationship between sleep duration and BMI in women. However, the distribution of sleep duration and obesity in the present study corresponds with the data from a Detroit population telephone interview self-reported sleep hour study ${ }^{28}$ and the Penn State Cohort results. ${ }^{36}$

The present study assessed the impact of carbohydrate overeating to determine if it is associated with obesity, using the 24-hour recall method. Young obese women did not report a higher carbohydrate intake, although there was a significantly higher carbohydrate intake in young obese people overall (Online Appendix 1). Therefore, the association between obesity in young women with short sleep duration could be attributable to other factors, which could not be identified in this study.

There were several limitations to our study. First, it is difficult to show causality between obesity and short sleep duration using a cross-sectional study design, although this study does demonstrate 
Table 2. Association between number of sleep hours and obesity after adjustment for age, sex, stress, socioeconomic position, health behaviors, and other clinical factors

\begin{tabular}{|c|c|c|c|c|}
\hline \multirow{2}{*}{ Variables } & \multicolumn{4}{|c|}{ Obesity (BMI > 25) } \\
\hline & Model 1 & Model 2 & Model 3 & Model 4 \\
\hline \multicolumn{5}{|l|}{ 20-64 years } \\
\hline \multicolumn{5}{|l|}{ All } \\
\hline$\geq 9$ hours & $1.71(1.38-2.12)$ & $1.45(1.17-1.81)$ & $1.47(1.13-1.92)$ & $1.59(1.20-2.12$ \\
\hline 6-8.9 hours & 1.0 & 1.0 & 1.0 & 1.0 \\
\hline$<6$ hours & $1.38(1.20-1.58)$ & $1.26(1.09-1.45)$ & $1.19(1.01-1.41)$ & $1.26(1.05-1.52$ \\
\hline \multicolumn{5}{|l|}{ Male } \\
\hline$\geq 9$ hours & 1.44 (1.06-1.96) & $1.38(1.01-1.88)$ & 1.37 (0.98-1.91) & $1.43(0.99-2.05)$ \\
\hline $6-8.9$ hours & 1.0 & 1.0 & 1.0 & 1.0 \\
\hline$<6$ hours & 1.14 (0.94-1.40) & $1.11(0.91-1.36)$ & 1.12 (0.91-1.39) & $1.18(0.94-1.49)$ \\
\hline \multicolumn{5}{|l|}{ Female } \\
\hline$\geq 9$ hours & $1.97(1.51-2.56)$ & 1.30 (0.98-1.71) & $1.48(0.98-2.21)$ & $1.80(1.17-2.75$ \\
\hline 6-8.9 hours & 1.0 & 1.0 & 1.0 & 1.0 \\
\hline$<6$ hours & $1.79(1.50-2.13)$ & $1.45(1.21-1.73)$ & 1.31 (1.01-1.70) & $1.38(1.03-1.84$ \\
\hline \multicolumn{5}{|l|}{ 20-44 years } \\
\hline \multicolumn{5}{|l|}{ All } \\
\hline$\geq 9$ hours & $1.92(1.42-2.58)$ & $1.73(1.28-2.34)$ & $1.68(1.16-2.41)$ & 1.99 (1.32-2.99) \\
\hline 6-8.9 hours & 1.0 & 1.0 & 1.0 & 1.0 \\
\hline$<6$ hours & $1.43(1.16-1.75)$ & $1.44(1.17-1.77)$ & $1.36(1.07-1.73)$ & $1.40(1.08-1.82$ \\
\hline \multicolumn{5}{|l|}{ Male } \\
\hline$\geq 9$ hours & $1.65(1.06-2.57)$ & $1.54(0.98-2.41)$ & 1.60 (0.99-2.58) & $1.78(1.04-3.04$ \\
\hline 6-8.9 hours & 1.0 & 1.0 & 1.0 & 1.0 \\
\hline$<6$ hours & $1.21(0.90-1.61)$ & $1.23(0.92-1.65)$ & $1.25(0.92-1.70)$ & $1.31(0.95-1.81)$ \\
\hline \multicolumn{5}{|l|}{ Female } \\
\hline$\geq 9$ hours & $1.88(1.27-2.77)$ & 1.57 (1.06-2.33) & $1.73(1.02-2.96)$ & $2.41(1.28-4.54$ \\
\hline 6-8.9 hours & 1.0 & 1.0 & 1.0 & 1.0 \\
\hline$<6$ hours & $1.81(1.37-2.40)$ & $1.77(1.34-2.35)$ & 1.62 (1.12-2.34) & $1.56(1.02-2.37)$ \\
\hline \multicolumn{5}{|l|}{ 45-64 years } \\
\hline \multicolumn{5}{|l|}{ All } \\
\hline$\geq 9$ hours & $1.21(0.91-1.61)$ & 1.15 (0.97-1.37) & $1.19(0.84-1.69)$ & 1.22 (0.85-1.74) \\
\hline 6-8.9 hours & 1.0 & 1.0 & 1.0 & 1.0 \\
\hline$<6$ hours & $1.18(1.00-1.40)$ & 1.18 (0.89-1.57) & 1.06 (0.85-1.33) & $1.14(0.89-1.45)$ \\
\hline \multicolumn{5}{|l|}{ Male } \\
\hline$\geq 9$ hours & $1.15(0.76-1.74)$ & $1.16(0.77-1.75)$ & $1.10(0.71-1.70)$ & 1.07 (0.68-1.68) \\
\hline $6-8.9$ hours & 1.0 & 1.0 & 1.0 & 1.0 \\
\hline$<6$ hours & 1.03 (0.80-1.34) & $1.05(0.81-1.36)$ & 1.04 (0.79-1.37) & 1.09 (0.81-1.46) \\
\hline \multicolumn{5}{|l|}{ Female } \\
\hline$\geq 9$ hours & $1.28(0.86-1.89)$ & $1.15(0.77-1.72)$ & $1.27(0.72-2.24)$ & $1.46(0.81-2.64)$ \\
\hline $6-8.9$ hours & 1.0 & 1.0 & 1.0 & 1.0 \\
\hline$<6$ hours & $1.37(1.17-1.70)$ & $1.27(1.02-1.59)$ & $1.08(0.76-1.54)$ & $1.21(0.84-1.75)$ \\
\hline
\end{tabular}

Model 1 is a crude odds ratio (OR).

Model 2 is adjusted for age.

Model 3 is adjusted for age, sex, mental stress, education level, equivalent household monthly income level, walking, smoking, and drinking. Statistical analysis was applied except in sex analysis.

Model 4 is adjusted for model 3+systolic blood pressure, diastolic blood pressure, fasting blood sugar, triglycerides, and high density lipoprotein levels.

that obesity is associated with short sleep duration in young Korean females. Second, KNHANES did not investigate the quality of sleep or conduct a quantitative assessment of regular physical activity, drink, and smoking. Third, this study utilized self-reported sleep duration instead of measured sleep duration. However, good agree- ment between self-reported sleep durations and those obtained through actigraphic monitoring has been reported in previous studies. ${ }^{37}$ Therefore, our study supports the hypothesis that there is an association between short sleep duration and obesity.

This study is highly representative of the Korean population since 
All
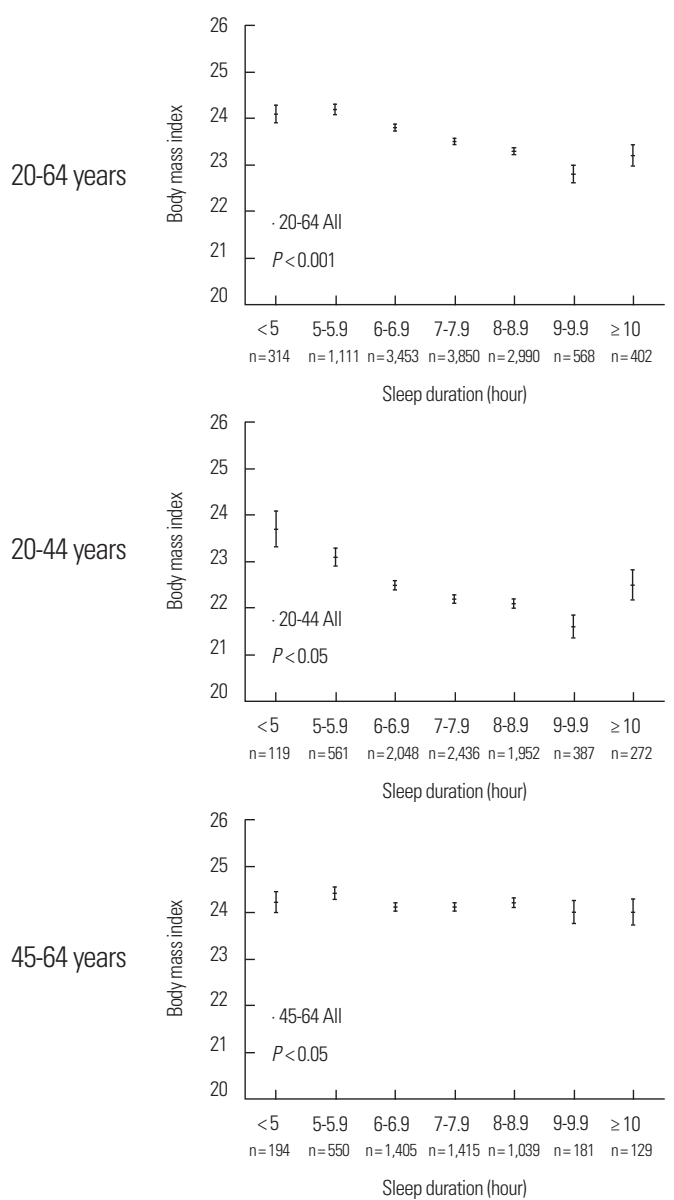

Male
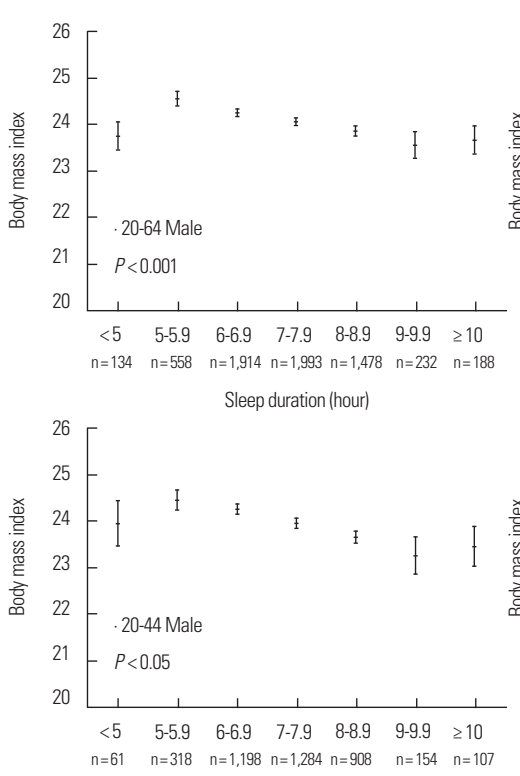

Sleep duration (hour)

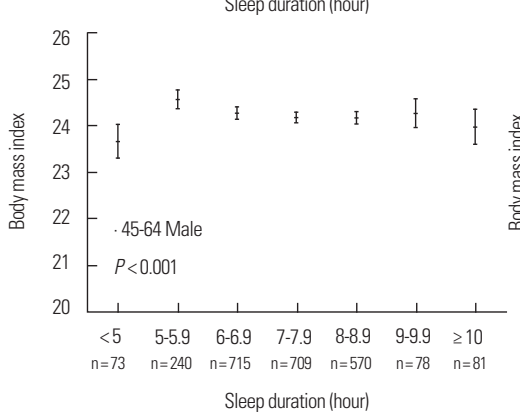

Female
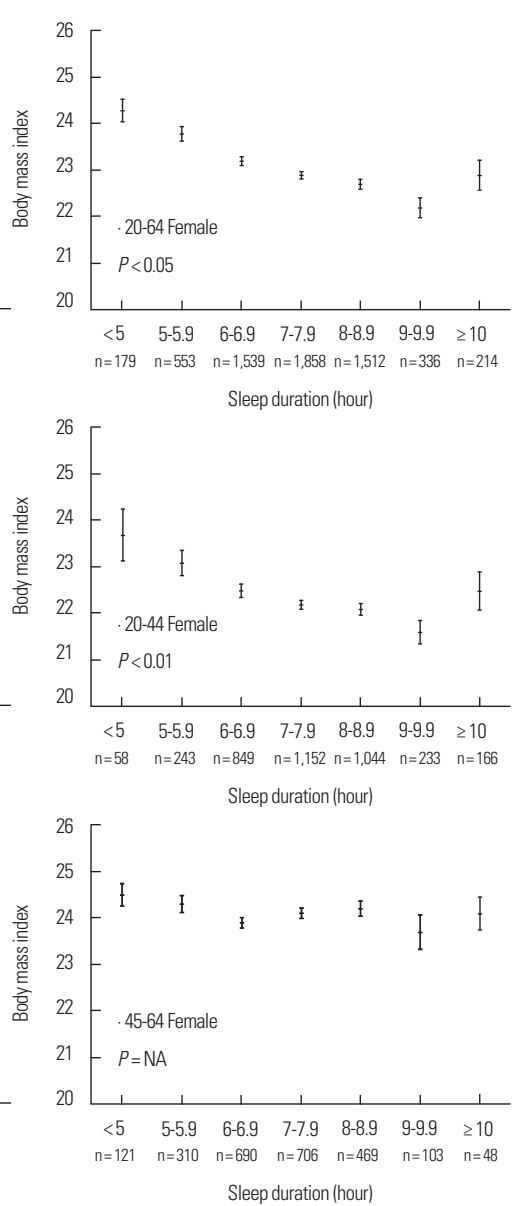

Figure 1. One-way analysis of variance of mean (standard error) body mass index (BMI) and sleep duration according to age and sex.

it is a well-designed random sample study. Therefore, our results are applicable to the general Korean population.

This community-based random sample was drawn from a population of young Korean adults, especially women, and indicated that short sleep duration was significantly associated with obesity. These finding may have important clinical implications for the prevention of obesity, especially in young women, since sleep duration is a potentially modifiable risk factor.

\section{Conflicts of Interest}

None Declared.

\section{References}

1. Gehrman P, Stepnowsky C, Cohen-Zion M, Marler M, Kripke DF,
Ancoli-Israel S. Long-term follow-up of periodic limb movements in sleep in older adults. Sleep 2002;25:340-3.

2. Vgontzas AN, Fernandez-Mendoza J, Liao D, Bixler EO. Insomnia with objective short sleep duration: the most biologically severe phenotype of the disorder. Sleep Med Rev 2013;17:241-54.

3. Vgontzas AN, Fernandez-Mendoza J. Insomnia with short sleep duration: nosological, diagnostic, and treatment implications. Sleep Med Clin 2013;8:309-22.

4. Ikehara S, Iso H, Date C, Kikuchi S, Watanabe Y, Wada Y, et al. Association of sleep duration with mortality from cardiovascular disease and other causes for Japanese men and women: the JACC study. Sleep 2009;32:295-301.

5. Ayas NT, White DP, Al-Delaimy WK, Manson JE, Stampfer MJ, Speizer FE, et al. A prospective study of self-reported sleep duration and incident diabetes in women. Diabetes Care 2003;26:380-4. 6. Wolff B, Völzke H, Schwahn C, Robinson D, Kessler C, John U. 
Relation of self-reported sleep duration with carotid intima-media thickness in a general population sample. Atherosclerosis 2008;196: $727-32$.

7. Eguchi K, Pickering TG, Schwartz JE, Hoshide S, Ishikawa J, Ishikawa S, et al. Short sleep duration as an independent predictor of cardiovascular events in Japanese patients with hypertension. Arch Intern Med 2008;168:2225-31.

8. King CR, Knutson KL, Rathouz PJ, Sidney S, Liu K, Lauderdale DS. Short sleep duration and incident coronary artery calcification. JAMA 2008;300:2859-66.

9. Kripke DF, Garfinkel L, Wingard DL, Klauber MR, Marler MR. Mortality associated with sleep duration and insomnia. Arch Gen Psychiatry 2002;59:131-6.

10. Centers for Disease Control and Prevention (CDC). Unhealthy sleep-related behaviors--12 States, 2009. MMWR Morb Mortal Wkly Rep 2011;60:233-8.

11. Nelson TD, Lundahl A, Molfese DL, Waford RN, Roman A, Gozal D, et al. Estimating child sleep from parent report of time in bed: development and evaluation of adjustment approaches. J Pediatr Psychol 2014;39:624-32.

12. Stranges S, Cappuccio FP, Kandala NB, Miller MA, Taggart FM, Kumari M, et al. Cross-sectional versus prospective associations of sleep duration with changes in relative weight and body fat distribution: the Whitehall II Study. Am J Epidemiol 2008;167:321-9.

13. OECD. Society at a glance 2009: OECD social indicators, Chapter 2. Special Focus: Measuring leisure in OECD Countries [accessed 2016 Jun 1]; Available from: URL: http://www.oecd.org/berlin/ 42675407.pdf

14. The Korea Institute for Health and Social Affairs for the Korean Ministry of Health and Welfare, The Korean Ministry of Health and Welfare. 2007-2009 The Forth Korea National Health and Nutrition Examination Survey. [accessed 2016 Jun 1]; Available from: URL: https://knhanes.cdc.go.kr/knhanes/index.do

15. Chaput JP, Després JP, Bouchard C, Tremblay A. The association between short sleep duration and weight gain is dependent on disinhibited eating behavior in adults. Sleep 2011;34:1291-7.

16. Anic GM, Titus-Ernstoff L, Newcomb PA, Trentham-Dietz A, Egan KM. Sleep duration and obesity in a population-based study. Sleep Med 2010;11:447-51.

17. Magee CA, Iverson DC, Caputi P. Sleep duration and obesity in middle-aged Australian adults. Obesity (Silver Spring) 2010;18:
420-1.

18. Vioque J, Torres A, Quiles J. Time spent watching television, sleep duration and obesity in adults living in Valencia, Spain. Int J Obes Relat Metab Disord 2000;24:1683-8.

19. Weisell RC. Body mass index as an indicator of obesity. Asia Pac J Clin Nutr 2002;11 Suppl 8:S681-4.

20. Bassett J; International Diabetes Institute; World Health Organization Regional Office for the Western Pacific; International Association for the Study of Obesity; International Obesity Task Force. The Asian-Pacific perspective: redefining obesity and its treatment. Melbourne: Health Communications Australia; 2000.

21. OECD. Organization for Economic Cooperation and Development (OECD): What are equivalence scales? [accessed 2016 Jun 1]; Available from: URL: http://www.oecd.org/dataoecd/61/52/35411111.pdf

22. The Korea Institute for Health and Social Affairs for the Korean Ministry of Health and Welfare, The Korean Ministry of Health and Welfare. 2005 The Third Korea National Health and Nutrition Examination Survey. [accessed 2016 Jun 1]; Available from: URL: https://knhanes.cdc.go.kr/knhanes/index.do

23. Gangwisch JE, Malaspina D, Boden-Albala B, Heymsfield SB. Inadequate sleep as a risk factor for obesity: analyses of the NHANES I. Sleep 2005;28:1289-96.

24. Buscemi D, Kumar A, Nugent R, Nugent K. Short sleep times predict obesity in internal medicine clinic patients. J Clin Sleep Med 2007;3:681-8.

25. Jean-Louis G, Williams NJ, Sarpong D, Pandey A, Youngstedt S, Zizi F, et al. Associations between inadequate sleep and obesity in the US adult population: analysis of the national health interview survey (1977-2009). BMC Public Health 2014;14:290.

26. Hasler G, Buysse DJ, Klaghofer R, Gamma A, Ajdacic V, Eich D, et al. The association between short sleep duration and obesity in young adults: a 13-year prospective study. Sleep 2004;27:661-6.

27. Moraes W, Poyares D, Zalcman I, de Mello MT, Bittencourt LR, Santos-Silva R, et al. Association between body mass index and sleep duration assessed by objective methods in a representative sample of the adult population. Sleep Med 2013;14:312-8.

28. Singh M, Drake CL, Roehrs T, Hudgel DW, Roth T. The association between obesity and short sleep duration: a population-based study. J Clin Sleep Med 2005;1:357-63.

29. Hairston KG, Bryer-Ash M, Norris JM, Haffner S, Bowden DW, Wagenknecht LE. Sleep duration and five-year abdominal fat ac- 
cumulation in a minority cohort: the IRAS family study. Sleep 2010;33:289-95.

30. Taheri S, Lin L, Austin D, Young T, Mignot E. Short sleep duration is associated with reduced leptin, elevated ghrelin, and increased body mass index. PLoS Med 2004;1:e62.

31. Knutson KL, Van Cauter E. Associations between sleep loss and increased risk of obesity and diabetes. Ann N Y Acad Sci 2008; 1129:287-304.

32. Parry BL, Martínez LF, Maurer EL, López AM, Sorenson D, Meliska CJ. Sleep, rhythms and women's mood. Part I. Menstrual cycle, pregnancy and postpartum. Sleep Med Rev 2006;10:129-44.

33. Park S, Cho MJ, Chang SM, Bae JN, Jeon HJ, Cho SJ, et al. Relationships of sleep duration with sociodemographic and health-related factors, psychiatric disorders and sleep disturbances in a community sample of Korean adults. J Sleep Res 2010;19:567-77.
34. Vgontzas AN, Fernandez-Mendoza J, Miksiewicz T, Kritikou I, Shaffer ML, Liao D, et al. Unveiling the longitudinal association between short sleep duration and the incidence of obesity: the Penn State Cohort. Int J Obes (Lond) 2014;38:825-32.

35. Patel SR, Malhotra A, Gottlieb DJ, White DP, Hu FB. Correlates of long sleep duration. Sleep 2006;29:881-9.

36. Vgontzas AN, Lin HM, Papaliaga M, Calhoun S, Vela-Bueno A, Chrousos GP, et al. Short sleep duration and obesity: the role of emotional stress and sleep disturbances. Int J Obes (Lond) 2008; 32:801-9.

37. Ma CC, Burchfiel CM, Charles LE, Dorn JM, Andrew ME, Gu JK, et al. Associations of objectively measured and self-reported sleep duration with carotid artery intima media thickness among police officers. Am J Ind Med 2013;56:1341-51. 